ORIGINAL ARTICLE

\title{
The Barrow-in-Furness legionnaires' outbreak: qualitative study of the hospital response and the role of the major incident plan
}

\author{
A F Smith, C Wild, J Law
}

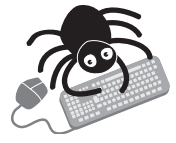

An appendix to this paper has been posted online at http://www.emjonline. com/supplemental/

See end of article for authors' affiliations

........................

Correspondence to:

Dr Andrew Smith

Department of

Anaesthesia, Royal

Lancaster Infirmary

Lancaster LA1 4RP, UK;

Andrew.Smith@rli.mbht

nhs.uk

Accepted for publication 29 March 2004

Objective: To document the organisational response of Furness General Hospital to the large outbreak of legionnaire's disease in April 2002 and assess the contribution made by the hospital's major incident plan.

Method: Qualitative analysis of interview transcripts and written comments from some staff involved in the management of the incident. Documentary analysis of major incident plan and other written materials.

Results: The incident posed considerable managerial and clinical problems and this paper describes how they were overcome. In particular, strategies for dealing with supply (of staff, beds, and resources) and managing demand (by liaising with primary care and the public) seem to have been successful. Many functions necessary for managing the incident were poorly dealt with in the plan, especially procedures for handling the news media and liaison with agencies outside the hospital. Lack of explicit guidance appeared not to hinder the organisational response. There may have been an unspoken high level decision to allow staff to draw on their skills and experience in improvising a response to the initial challenge and learning adaptively as the incident unfolded. There was also evidence that staff disregarded existing job and role boundaries and focused instead on tasks, working flexibly to ensure that these tasks were completed.

Conclusions: Protracted major incidents pose particular management challenges and may benefit from an approach different from that set out in typical major incident plans. Staff must be able to act flexibly and responsively. Some form of checklist or toolkit may be preferable to a detailed plan for some types of incident.

In the summer of 2002 the 400 bed Furness General Hospital, Cumbria, had to deal with the largest ever outbreak of legionnaire's disease in the UK, with 498 suspected cases being admitted over 10 days. ${ }^{1}$ The outbreak was caused by a contaminated ventilation plant in the town centre. Although this posed considerable clinical and organisational challenges for the hospital, mortality (about $3 \%)$ was lower than in other outbreaks. ${ }^{2}$

Major incident planning assumes that incidents are acute events of clearly defined onset. ${ }^{45}$ "Biological" incidentswhether due to bioterrorism or, as in this case, natural causes-are less well defined in onset and location. In these circumstances other policies may be more appropriate. ${ }^{6}$ We have not, however, been able to find any published reports of any type of incident which describe how plans are actually used. The aims of this paper are to:

- document how the incident was handled through participants' own accounts

- compare this with the organisation's major incident plan

- explore the reasons for, and consequences of, divergence between them.

\section{METHODS}

With the local research ethics committee's approval, we conducted loosely structured, tape-recorded interviews with purposively sampled trust staff and other significant individuals involved in the response to the outbreak. A public appeal was made by poster and email to all staff within the hospital trust for further comments and opinions. This allowed some triangulation of data but we also intended to give voice to unrecognised groups within the hospital. Interview transcripts and written staff comments were analysed by the constant comparative method, ${ }^{7}$ involving the colour coding of field notes into themes and the extensive use of exemplar cases to allow the identification of themes. Factual matters were corroborated where necessary with documentary material from the time of the outbreak and the reported responses were compared with the hospital's major incident plan. Emerging themes were fed back to some interviewees (respondent validation ${ }^{8}$ ) for comment and clarification.

\section{RESULTS}

We have data from 15 interviews (box l) and seven written submissions from other staff (box 2). The themes identified are listed in table 1. Furness General Hospital's major incident plan was drawn up and published in September 1997 and follows the UK Department of Health guidelines ${ }^{9}$ in setting out clearly the roles to be taken by certain key clinical and some other staff. It runs to 56 pages of text with an additional 10 pages of appendices. A short introductory section on definitions and general policy deals with the declaration of an incident and sets out where the necessary facilities are to be located. The two key roles of medical coordinator and triage officer are defined. Further recommendations are made on documentation, the deployment of the mobile medical team, tracking of patients and debriefing after the incident. A short section on management of casualties on arrival follows, then the rest of the main body of the text itemises the actions required of specific individuals and groups of staff likely to be involved in the response. These are principally for clinical staff, although telephonists, 


\section{Box 1: List of interviewees}

- Primary care trust representative

- Directorate manager

- Medical director

- Police officer

- Modern matron

- Senior manager

- Supplies manager

- Intensive care nurse

- General practitioner

- Information systems manager

- Ambulance officer

- Nurse manager

- Microbiologist

- Medical secretary

- Consultant anaesthetist

medical records, the central sterile supplies department (CSSD), and the staff of the postgraduate library are also listed. For many tasks, which in hindsight appear to have been crucial to the management of the outbreak, there is no guidance on how to carry out the functions set. This means that the individuals taking on these roles must draw on their experience and initiative in carrying them out. Yet the major incident plan fulfils many of the Department of Health's Emergency Planning Co-ordination Unit's recommendations in force at the time.

\section{Declaring an incident and using the plan}

The Trust's plan defined an incident as "the arrival, or anticipated arrival, of many more casualties ... than the Accident and Emergency Department is staffed to handle at that particular time". There was initial ambiguity about the possible scale of the outbreak, but the decision was taken that it was preferable to begin major incident procedures and stand down later if necessary. An incident room was established in the hospital on the morning of Friday, 2 August 2002, and by mid-afternoon the hospital switchboard and the local media were informed. The plan itself was never fully activated, nor was any other written document or policy referred to. One senior manager with experience of other major incidents felt that incident plans were of limited use in guiding the response:

Interview 6 (senior manager): I actually think that in the event of a major incident the best thing you can do with it is put it in the bin, because you get people following a policy and rigidly trying to apply what it says on the piece of paper in circumstances which don't meet that piece of paper ... [it is worth] reading the table of contents to make sure you haven't missed anything, it tells you about things like catering, security, mortuary facilities. As far as experienced operational managers are concerned, I don't think it is of huge benefit when it gets to the incident [though] it's of huge benefit beforehand in practising and planning.

The management strategy focused on managing supply (of patients to the hospital) and demand (for beds, staff, and supplies). The first aim was effected by working with general practitioners and the local population. In essence, a "reverse

\section{Box 2: List of written responses}

- Clinical coding officer

- Clinical systems officer, development directorate

- Catering officer

- Staff nurse at another hospital in the trust

- Human resources manager at another hospital in the trust

- Administrator

- Critical care manager

Table 1 List of themes identified from interview transcripts and written responses

\begin{tabular}{|c|c|}
\hline Communication & $\begin{array}{l}\text { Internal } \\
\text { External }\end{array}$ \\
\hline Resources & $\begin{array}{l}\text { Staff } \\
\text { Material } \\
\text { Luck }\end{array}$ \\
\hline Flexibility & $\begin{array}{l}\text { Levels of risk } \\
\text { Breadth of roles } \\
\text { About major incident plan }\end{array}$ \\
\hline Progress and change & $\begin{array}{l}\text { Organisational learning } \\
\text { Information technology } \\
\text { Media handling }\end{array}$ \\
\hline Forward planning & \\
\hline
\end{tabular}

cascade" system was operated, whose aim was for the public to keep the pressure off general practitioners, who in turn were to help keep the pressure off the Accident and Emergency (A\&E) department at the hospital. If patients were seen in A\&E, staff tried to send as many patients home with treatment as possible, to keep the pressure off the wards, and the hospital wards tried to work proactively with critical care staff to regulate the demand for intensive care. Extra bed capacity was created by stopping elective surgery at Furness General. The rapid turnover of surgical admissions meant that beds quickly became free. The speed of influx of the legionnaires' cases-more gradual than in a typical major incident-helped better matching of admission to beds. Furness's sister hospital in Lancaster was also put on standby in case of overflow. These "medical" patients were also admitted to wards other than medical wards. For instance, the day hospital was converted to a medical ward, the five day surgical ward was made into an inpatient ward. This "medical bed area" gradually expanded to include the daycare ward but not the gynaecology wards, which would have been the next to be used. Bed state information was frequently updated to allow a "buffer" of 15 empty beds to be maintained at all times. An "early warning scoring" system was used on the wards to help in the recognition of patients in need of critical care advice or referral.

The decision was taken not to compromise quality of intensive care unit (ICU) care by expanding capacity. Instead, a similar "buffer" policy was operated in the ICU, where one bed was kept free at all times. Patients thought to be deteriorating were transferred to neighbouring ICUs before mechanical ventilation became necessary. Staff responded to the crisis by returning from leave and working longer shifts than usual. Other staff were drafted in from elsewheremost notably, nurses from the community. However, there were challenges too in sustaining the necessary level of response for such a prolonged period: 
Interview 3 (medical director): You need to expand capacity and resources to meet the problem, which involves getting staff in, deploying them, and in this instance making sure that they're not over working. In a major accident because it's all done and dusted by the next morning there isn't an ongoing commitment. Here there was and we had to be quite careful about sending people home. People are very willing to come in and help out but we had to make sure that they didn't exhaust themselves.

The functions of those in the incident room are managerial rather than clinical. They take an overview of the situation and the infrastructure needed to deliver care, provide information, and coordinate activity. In the present situation the room contained the chief executive, the medical director, a nursing manager, and an information systems specialist. There were also representatives from the police and ambulance services. The room was equipped with telephones, a fax machine, computers, and whiteboards. The staff issued regular clinical updates (twice daily in the early stages), monitored bed states in the hospital and all regional ICUs, dealt with equipment needs, the transport of specimens to the Public Health Laboratory Service (PHLS), Colindale, held and passed on pathology results, and liaised with hospital staff and all external bodies. The incident room was established in the recommended site in the A\&E department. An advantage of this is that it is close to the admissions unit and also the primary care cooperative office. However, the designated room is probably too small for such prolonged use.

Keeping track of patients is one of the foremost necessities in any major incident. Purpose designed major incident casenotes, numbered from 1 to 150, are kept in the A\&E department and the plan details the contents of these. These casenotes were not used in the legionnaires' outbreak. Instead, a computer database was established and maintained for the duration of the outbreak and for some time thereafter. The need for this had become apparent during a major incident test, then a small scale live incident, earlier in 2002. The database was refined as time went on, and was also linked to the NSTS system (NHS Strategic Tracing Service), which was also still in development at that time. The information and technology (IT) department thus played a major role in the outbreak, in contrast with the major incident plan, which refers to the IT department only as a holding area for the news media.

\section{"Wider worlds"}

The management of any major incident involves other services and agencies. However, there were particular aspects to this incident which are worth mentioning.

Perhaps the most significant was the involvement of the news media. The major incident plan contains little mention of the media. The local radio station is to be asked to broadcast a request for off-duty staff to report to the hospital, but no further guidance is given. In the event there was substantial media interest in the outbreak:

Interview 6 (senior manager): I made the decision that we would be proactive with the press before it started leaking out. We called the press conference and were taken aback by the amount of press interest. We expected it to be big and have national coverage. We didn't expect all the international televisions crews that turned up, but it was August and there wasn't a lot going on. We tried to be as honest as we could. I did a deal with the press up front, that as long as they behaved themselves I would keep them well informed. I would where appropriate give them access to patients' relatives (with their consent), we would issue four hourly press releases and update bulletins. They were actually very responsible and I think we kept our side of the bargain.

Although dealing with the media took time and energy, it had some benefits. The local population appeared to respond with fewer non-legionnaires' self-referrals to the hospital. Other hospitals in the region quickly realised the scale of the problem and were readier to help if required. Furthermore, the regular news bulletins proved useful for distribution within the hospital too.

The ambulance service was also clearly under pressure during the outbreak. However, its involvement brought a number of benefits. Frequent contact with the ICU enabled inter-hospital transfers to be arranged more efficiently than usual, and a member of the ambulance service also was available within the hospital to assist with venous cannulation (repeat cannulation was often necessary because if the irritant nature of the antibiotics used to treat Legionella).

The police were also closely involved because of the possibility of legal action relating to the source of the outbreak but initially faced some difficulty pursuing their inquiries:

Interview 4 (police officer): We didn't want the patient notes or anything. All we wanted was the name and address and where they were in the hospital so we could go and see them. So we weren't asking for a lot but it was just this big barrier. Ultimately the Chief Executive said it was in the public interest to tell the police, so an agreement was made. That was superb because that allowed us to go on from there. If it wasn't a legionnaires' outbreak, if it was a terrorist attack where 100 people had been machine-gunned down, we would just have been given the details. People across the board couldn't understand why we were here and why it was a police investigation.

Again, cooperation brought unanticipated benefits: for instance, the police were able to arrange air transport of samples to London.

\section{The role of tacit knowledge}

Legionnaires' disease, though well known, is infrequently seen in clinical practice and staff needed to be reminded of the principles of management. Dealing with patients with suspected Legionella was made easier by the introduction of a purpose written admission pro forma by the A\&E department early in the incident (see appendix online at http:// www.emjonline.com/supplemental/). Lunchtime educational meetings on the subject were promptly arranged for local general practitioners also. Thus, the explicit knowledge needs of staff during the outbreak were quickly recognised and addressed.

However, much of the knowledge used by staff in the outbreak was tacit and relied on intimate acquaintance with the local context. This is illustrated by the following respondent but also suggests that staff from elsewhere, although clearly skilled and willing to help, may be of limited use:

Interview 2 (directorate manager): We had a lot of people who didn't know their way around the site coming up trying to do things and trying to give information out and not knowing where they were going or who they should be talking to-people from other sites, people from other 
directorates who didn't know [the hospital layout] and some of that needs to be reviewed as to who you use.

Experienced staff also drew on their knowledge and experience (sometimes from previous jobs and roles) to anticipate problems and form their own strategy for dealing with them:

Interview 12 (nursing manager): It got to probably $4.35 \mathrm{pm}$ or so and I thought to myself this place is absolutely heaving .... and I thought oh-oh-nights!

We only have one night sister on duty at night ... so I checked with the Head of Nursing and said I should actually go home, sort a uniform out and come back in and work with the night sister. ... from then on I just worked night duty through to a week on Saturday.

This contrasts with the incident plan, whose "action cards" detail quite closely the duties required of each holder.

\section{DISCUSSION}

We have outlined some of the aspects of the management of a large outbreak of legionnaires' disease. Although we are confident that our account of the outbreak is factually accurate, any further inferences drawn from our data must be interpreted with caution because of our method of selecting interviewees. Close comparison with the incident plan is unfair as it was already five years old at the time of the outbreak, and could not be expected to guide such a prolonged and complex response. Further, it could be argued that the major incident plan is less appropriate than more specific outbreak policies and the closer involvement of the infection control team might have been considered. We have no data to support these arguments, though it is clear that the outbreak guidance required in $1988,{ }^{6}$ for instance, has been rendered less relevant both by its age and several reorganisations of health service administration. We feel that, as the major incident plan was the only document drawn on at all during the outbreak, the areas of divergence between plan and practice we have identified may be of relevance to the handling of future incidents.

Firstly, this study raises questions as to the usefulness of written plans and policies in incidents such as this. The view was expressed that the plan was vital in practising and rehearsing for an incident but less helpful in a real incident. The ideal major incident plan should enable thinking ahead, planning for incidents, and testing responses. It should also help during a real incident. However, a single document may not serve both purposes. During planning, we advocate a wider systems approach (see below). In the context of an actual incident, we would advocate a simple checklist of issues and personnel as an aide memoire rather than a detailed specification which may not, as we have demonstrated, suit all eventualities. Redesigning major incident plans as adaptable "toolkits" to better meet both needs may be a useful measure.

Secondly, it is clearly vital to involve the wider health economy and other agencies during both the planning process and the actual incidents. (As an aside, an integrated response would probably have been easier when health authorities managed hospitals directly.) Staff in primary care can play a major role in keeping the pressure off hospitals. The goodwill generated by cooperation with the police led to assistance with transportation of medical supplies by police aircraft and the presence of an ambulance officer on ICU brought great efficiency in scheduling patient transfers. Proper preparation, for instance for a biological attack, ${ }^{10}$ implies collaboration and although this has been addressed in part with the formation of health protection agencies ${ }^{11}$ our findings underline this. The outbreak required collaboration between, amongst others, the primary care trust, the local authority, and the Health and Safety Executive. Links with the news media were also much more important than expected.

Thirdly, we would wish to draw attention to an organisational issue which was not articulated by the respondents themselves. We detected two distinct, though intersecting levels of work in this outbreak. On the one hand, the intense activity in the incident room was principally concerned with external links and ensuring that the resources necessary for the handling of the outbreak were provided. Clinical activity within the hospital seems to have proceeded almost in its own "world of work". We suggest that whether consciously or not, those working in the incident room created the organisational "space" to allow other staff to simply get on with exercising their professional skills in the handling of the outbreak. This seems to have fostered both flexibility of working and willingness to sanction risk taking. In doing this staff drew mostly on their own experiential, tacit knowledge in their responses to the outbreak, not the formalised, explicit prescriptions of the incident plan. The central role of tacit knowledge is increasingly recognised in organisations ${ }^{12}{ }^{13}$ and professions $^{14}{ }^{15}$ and a knowledge management strategy is being developed for the National Health Service (NHS). ${ }^{16}$ Although our data do not allow us to relate these characteristics to patient outcome, we nevertheless suggest that they are linked. One characteristic of safety-critical "high reliability organisations" is that although they depend on a clear chain of command, they also require local, lowerlevel initiatives for success. ${ }^{17}$ In this outbreak there seems to have been high level clarity of purpose but much decision making was decentralised in that staff were mostly given the resources they needed and allowed to simply get on with the job of using their skills and experience to improvise solutions. The normal stringencies of protocol and accountability were relaxed and "risk taking", in the sense of trying out solutions which were of necessity new and untested, was favoured. People responded by worked flexibly not only in terms of number of hours and intensity of work, but also across conventional professional and administrative boundaries. It is interesting to note that the NHS Changing Workforce Programme is currently trying to promote such flexibilities. We suggest that willingness on the part of "lower status" staff in the organisation to take "responsible risks" in trying to find solutions must be matched by an acceptance higher up that this will necessarily involve making some mistakes.

\section{ACKNOWLEDGEMENTS}

We would like to thank all those who contributed either by taking part in interviews or submitting written responses. We are also grateful to the two anonymous referees who commented on an earlier version of this paper.

\section{CONTRIBUTORS}

AS and JL designed the study. AS helped analyse the data and wrote the paper. CW and JL collected and analysed the data and contributed to writing the paper. AS is guarantor for the work.

\section{Authors' affiliations}

A F Smith, C Wild, Research and Development Department, Morecambe Bay Hospitals NHS Trust, Royal Lancaster Infirmary, Lancaster, UK J Law, Department of Sociology, Cartmel College, Lancaster University, Lancaster, UK

Funding: UK Department of Health. The views expressed are those of the authors and not necessarily those of the Department of Health.

Competing interests: none declared 


\section{REFERENCES}

1 Joseph C. New outbreak of legionnaires' disease in the United Kingdom. BMJ 2002;325:347-8

2 Lettinga KD, Verbon A, Weverling GJ, et al. Legionnaires' disease at a Dutch flower show: prognostic factors and impact of therapy. Emerg Inf Dis 2002;8:1448-54.

3 Fernandez JA, Lopez P, Orozco D, et al. Clinical study of an outbreak of Legionnaires' disease in Alcoy, Southeastern Spain. Eur J Clin Microbiol Inf Dis 2002;21:729-35.

4 Wardrope J, Hockey MS, Crosby AC The hospital response to the Hillsborough tragedy. Injury 1990;21:53-4.

5 Clifton NJ, The M1 plane crash, managing a response' In: Wallace WA, Rowles JM, Colton CL, eds. Management of Disasters and Their Aftermath. London: BMJ Publishing, 1994.

6 Department of Health and Social Security. Hospital Infection Control, Health Circular. London: DHSS, 1988;(88):33.

7 Miles MB, Huberman MA. Qualitative Data Analysis; an Expanded Sourcebook. Thousand Oaks, CA: Sage, 1994

8 Hammersley M. Reading ethnographic research: a critical guide. New York, London: Longman, 1998.
9 NHS Executive. Emergency Planning in the NHS: Health Services Arrangements for dealing with Major Incidents. London: Department of Health, 1996.

10 National Audit Office. Facing the Challenge: NHS Emergency Planning in England. London: The Stationery Office, 2002.

11 Health Protection Agency website: www.hpa.org.uk (accessed 11 July 2003).

12 Davenport T, Prusak D. Working Knowledge. Boston: Harvard University Press, 1999.

13 Nonaka I, Takeuchi H. The Knowledge Creating Company. New York: Oxford University Press, 1995.

14 Smith AF, Goodwin D, Mort M, et al. Expertise in practice: ethnographic study of the acquisition and use of knowledge in anaesthesia. $\mathrm{Br} J$ Anaesth 2003;91:319-28.

15 Argyris C. Tacit knowledge and management. In: Sternberg RJ, Horvath JA eds. Tacit Knowledge in Professional Practice: Researcher and Practitioner Perspectives. Mahwah, NJ: Lawrence Erlbaum Associates Inc, 1999.

16 NHS National Electronic Library for Health. Knowledge management in the NHS. Available at www.nelh.nhs.uk/knowledge_management $/ \mathrm{kml} / \mathrm{nhs}$.asp (accessed 11 July 2003)

17 Roberts KH. Some characteristics of one type of high reliability organization. Organ Sci 1990;1:160-76.

\section{Register now!}

10th European Forum on Quality Improvement in Health Care 13-15 April 2005, ExCel Conference Centre, London For further information on how to register please go to: http://www.quality.bmipg.com 